\title{
Seven in 10 complaints reviewed under new GMC scheme are thrown out
}

\author{
Abi Rimmer
}

The BMJ

The General Medical Council carried out over 700 fewer fitness to practise investigations into complaints about doctors over the past two years, following a change to its processes.

The regulator investigated $18 \%$ of the complaints it received in 2016 (1436 out of 8197), compared with $31 \%$ in 2014 (2726 out of 8851). ${ }^{1}$

In its State of Medical Education and Practice in the UK report the regulator said that the drop in the number of investigations was linked to the introduction of a provisional enquiries process.

The process means that the GMC asks more questions about a complaint before it decides whether it needs to carry out a full investigation. Previously, the GMC would have started the full investigation before gathering this information.

The GMC said that the number of provisional inquiries gradually increased between 2014 and 2016, as the process was rolled out to cover different types of complaint.

Since 2014, when the process was introduced, 1001 complaints have been subject to provisional enquiry. Of these, 697 were closed immediately and 11 were referred to the doctors' employer.
A further 277 provisional enquiries led to a full GMC investigation and 16 are still being assessed.

The GMC said that it was piloting an expansion of the provisional enquiry process to include incidents where a doctor has made a one-off mistake involving poor clinical care.

The Medical Defence Union (MDU), welcomed the drop in the number of doctors who had to face a fitness to practise investigation by the GMC.

Catherine Wills, deputy head of advisory services at the MDU, said, "We know how stressful it can be for a doctor undergoing a GMC investigation and are pleased at the success of the measures put in place by the GMC to reduce the need for investigations at an early stage. These include provisional enquiries to identify cases that would not reach the GMC's threshold, even if the facts were proven."

General Medical Council. The state of medical education and practice in the UK. 2017 www.gmc-uk.org/static/documents/content/SoMEP-2017-final-full.pdf.

Published by the BMJ Publishing Group Limited. For permission to use (where not already granted under a licence) please go to http://group.bmj.com/group/rights-licensing/ permissions 